\title{
Alexithymia and emotional regulation: A cluster analytical approach
}

Jie Chen ${ }^{1,2,3}$, Ting $X u^{2,4}$, Jin Jing ${ }^{1}$, Raymond CK Chan ${ }^{2 *}$

\begin{abstract}
Background: Alexithymia has been a familiar conception of psychosomatic phenomenon. The aim of this study was to investigate whether there were subtypes of alexithymia associating with different traits of emotional expression and regulation among a group of healthy college students.

Methods: 1788 healthy college students were administered with the Chinese version of the 20-item Toronto Alexithymia Scale (TAS-20) and another set of questionnaires assessing emotion status and regulation. A hierarchical cluster analysis was conducted on the three factor scores of the TAS-20. The cluster solution was cross-validated by the corresponding emotional regulation.
\end{abstract}

Results: The results indicated there were four subtypes of alexithymia, namely extrovert-high alexithymia (EHA), general-high alexithymia (GHA), introvert-high alexithymia (IHA) and non-alexithymia (NA). The GHA was characterized by general high scores on all three factors, the IHA was characterized by high scores on difficulty identifying feelings and difficulty describing feelings but low score on externally oriented cognitive style of thinking, the EHA was characterized by high score on externally oriented cognitive style of thinking but normal score on the others, and the NA got low score on all factors. The GHA and IHA were dominant by suppressive character of emotional regulation and expression with worse emotion status as compared to the EHA and NA.

Conclusions: The current findings suggest there were four subtypes of alexithymia characterized by different emotional regulation manifestations.

\section{Background}

Alexithymia has been a familiar conception as "no words for feeling" in psychiatry and psychosomatic medicine since it was first termed by Sifneos [1]. Now its definition is more explicitly refined with five dominant features: (1) difficulty in identifying one's emotion; (2) difficulty in describing self feelings verbally; (3) a reduction or incapability to experience emotions; (4) an absence of tendencies to image one else's emotion, or an externally oriented cognitive style; and (5) poor capacity for fantasize or symbolic thought [2]. Alexithymia refers to a specific disturbance in emotional processing, especially reduced capabilities in verbalizing and realizing emotion. Longitudinal study also suggested that alexithymia was significantly associated with the severity

\footnotetext{
* Correspondence: rckchan@psych.ac.cn

${ }^{2}$ Neuropsychology and Applied Cognitive Neuroscience Laboratory; Key Laboratory of Mental Health, Institute of Psychology, Chinese Academy of Sciences, Beijing, PR China

Full list of author information is available at the end of the article
}

of depression [3], anxiety [4] and schizophrenia [5]. The prevalence rate of alexithymia is significantly higher in patients with psychosomatic disorders, such as eating disorder [6], fibromyalgia syndrome [7] and low-back pain [8], than control groups.

Researchers $[9,10]$ found alexithymia overlaps with various dimensions like external locus of control and irrational beliefs, except impulsiveness, of the FiveFactor Model (FFM) of personality in an undergraduate student sample. It has been speculated that alexithymia is a cognitive state of externally oriented thinking with an emotional instability and unsecure performance in controlling stressful situation. However, alexithymia has also been criticized whether it is an affect-deficit disorder (state-orient) or a continuous personality variable (trait-orient). Tolmunen et al. [11] considered alexithymia as a stable personality trait in general. Their 11-year follow-up study also suggested that alexithymia might increase vulnerability to depressive symptoms [11]. Honkalampi [12] further demonstrated that depressive 
symptom might act as a mediator between alexithymia and psychiatric morbidity. Parker and Mattila used taxometric analysis to synthesize several studies about alexithymia in large sample pools including general population and psychotic patients $[11,12]$. These findings suggest that "aleixhtymia is not a discrete affect deficit type of person but represents 'the lower tail' of an emotion processing ability that is continuously distributed in the general population" [11].

The purpose of this study was to examine whether there might be subtypes of alexithymia characterized by different behavioural manifestations. In so doing, the current study adopted a cluster analytical approach to examine whether there were natural grouping of people characterized by different psychological features associating with alexithymia. Cluster analysis is a statistical procedure for determining cases can be placed into groups if they share properties in common, while the cases in different clusters are as dissimilar as possible. It was hypothesized that there were various subtypes of alexithymia characterized by different psychological features associating with alexithymia.

Individuals on various level of alexithymia would adopt different ways to express and regulate their emotion. The higher alexithymia groups would perform more serious level of depressive or anxious emotional status and more possible to adopt improper regulation strategy.

\section{Method}

\section{Participants}

1788 college students (freshmen and sophomore) were recruited from three regional universities in Guangzhou, south China. 1071 were males and 616 were females, aged $20.44 \pm 1.40$ years and $20.51 \pm 1.39$ years respectively, 101 individual did not mention their gender or age. Economic status was also recorded by a multiplechoice question in the checklist for monthly income per person a month. Among all subjects, 110 individuals did not mention their economic status.

All subjects were literarily informed the aim of current study was to examine about psychological status of Chinese youngsters and were voluntarily attended this study. All of them would receive a feedback on the assessment results via email. This study was approved by the ethics committee of the Sun Yat-Sen University.

\section{Measurements}

Alexithymia was assessed by the 20-item Toronto alexithymia scale (TAS-20) to assess the severity of alexithymia $[13,14]$. It is a 20 -item self-report instrument rated on a 5 -point Liker-type scale ranging from 1 (strongly disagree) to 5 (strongly agree). Total scores range from 20 to 100 , with higher scores indicating higher level of alexithymia. Within the five criteria, the TAS-20 consists of 3 factors: difficulty identifying feelings (DIF); difficulty describing feelings (DDF); externally oriented cognitive style of thinking (EOT). The Chinese version has been shown with having the same factor structure of the original version and has been associated with good internal consistency [15], which was adopted in this study. The Cronbach's $\alpha$ coefficient of it was 0.83 , the test-retest reliability coefficient was 0.87 , the mean inter-item correlation coefficients ranged from 0.13 to 0.32 , the correlate on coefficients of the three factors with the total scale score ranged from 0.72 to 0.82 , the correlation coefficients among the three factors ranged from 0.29 to 0.54 [16].

Emotion expression tendency was assessed by the Chinese version of the Emotional Expressivity Scale (EES) [17]. It is a 17-item self-report assessing the ability to express emotion rated on a 6-point Liker-type scale (1 = never true to 6 = always true). There were two factors in the Chinese version, namely the emotional suppression and emotional expression [18]. The Cronbach's alpha coefficient for the total scale showed a high internal consistency reliability of 0.816 . Cronbach's alphas for the two factors were 0.84 and 0.78 respectively indicating adequate internal consistency [18]. Higher total score reflects a higher ability to express emotion, higher expressive factor score means higher intention to express, but lower suppressive factor score means higher inclination to control emotion.

Emotion Regulation Questionnaire (ERQ) [19] was used to measure emotion regulation. The ERQ is a 10-item checklist capturing two commonly used emotion regulation strategies, i.e., reappraisal and suppression. Reappraisal refers to the use of methods changing the way of thinking about a potential emotional event, whereas suppression refers to the adoption of regulation to suppress when facing the same emotional event. Subjects were required to rate their respond to a 7-point Liker-type scale ( $1=$ totally disagree to $7=$ totally agree) on their usual ways of emotional regulation. The test-retest reliability and a coefficient of Chinese version of ERQ were 0.82 and 0.85 for reappraisal dimension, were 0.79 and 0.77 for suppression [20]. Higher score indicates a higher tendency to adopt such strategy. Reappraisal strategy was thought to be a more appropriate way to regulate emotion than suppression one.

Depression was measured with the Beck depression inventory (BDI) [21,22]. It is a 21 -item scale to assess depression problems with higher score representing more depression tendency. The current study adopted the Chinese version of BDI, which Cronbach's alpha coefficient was found to be 0.85 [23].

Anxiety was assessed with the Chinese version of the state portion of State-Trait Anxiety inventory 
(STAI-T) [24]. This is a self-reported scale containing 20 items assessing level of anxious status rated on a 4point Liker-type scale $(1=$ never to $4=$ always $)$. The Cronbach's alpha coefficient showed a high internal consistency reliability was 0.81 . The higher score refers a more serious anxious state.

\section{Data analysis}

The Statistical Package for Social Sciences (SPSS) 15.0 (SPSS Inc, Chicago, IL, USA) was used for all statistical analyses reported.

Independent sample $\mathrm{t}$-tests were conducted to analyze the gender effect on the total scores of TAS-20. ANOVA was conducted to evaluate the potential effect of economic status upon the total scores of TAS-20, whereas correlation analyses were used to explore any association of education and age with the TAS-20 scores.

Cluster analyses were conducted in two phases. First, a hierarchical cluster analysis was conducted using the 3 factors: difficulty identifying feelings; difficulty describing feelings; externally oriented cognitive style of thinking scores of TAS-20 as the clustering variables and the between-group linkage method with a squared Euclidean distance measure to discriminate clusters. Second, the cluster solution was validated with analysis of variance (ANOVA) on scores of Emotional Expressivity Scale with its subscales, Emotion Regulation Questionnaire, Beck depression inventory and the state portion of State-Trait Anxiety inventory of the identified groups.

\section{Results}

No significant difference was found in the total mean TAS-20 scores between boys and girls (49.63; SD, 8.70 vs $48.96 ; \mathrm{SD}, 8.60 ; \mathrm{p}=0.13$ ). Age was significantly correlated the total mean TAS-20 $(\mathrm{r}=0.05, \mathrm{p}=0.04)$, whereas there was no significant association between education and TAS-20 total score $(\mathrm{r}=0.04, \mathrm{p}=0.11)$. No significant different in the total mean TAS-20 scores between economic status was found $(\mathrm{F}=2.06, \mathrm{p}=0.08)$. Given the effect of age upon the TAS-20 score was negligible, it was not controlled for subsequent analyses between cluster comparisons.

Table 1 shows there were four subtypes of alexithymia groups, namely extrovert-high alexithymia (EHA), general-high alexithymia (GHA), introvert-high alexithymia (IHA) and non-alexithymia (NA). The extrovert-high alexithymia (EHA) group was characterized a relative high in externally oriented cognitive style, regular scores in difficulty identifying feelings and difficulty describing feelings and contained most of the cases (77.3\%). The general-high alexithymia (GHA) group was characterized by a high score of every factor of alexithymia. The introvert-high alexithymia (IHA) was characterized by a significant high score in difficulty identifying feelings and difficulty describing feelings, which referring to self emotional experience, but relative low score in externally oriented cognitive style of thinking scores. Finally, the non-alexithymia (NA) group was characterized a general low score of alexithymia problems.

The four clusters did not differ significantly in terms of gender propotion (Chi-square $=0.84, \mathrm{df}=3, \mathrm{p}=$ 0.84 ) and economic status (Chi-square $=16.18, \mathrm{df}=12$, $\mathrm{p}=0.17)$. However there showed significant difference in terms of age $(t=3.20, p=0.02)$ and education $(t=$ 3.85, $\mathrm{p}=0.01$ ).

An ANOVA showed that the four subtypes of alexithymia differed significantly in terms of emotional status, emotional expression and regulation as our estimation (Table 2). The general-high alexithymia (GHA) and introvert-high alexithymia (IHA) groups showed dominant higher level of depression and anxious than the extrovert-high alexithymia (EHA) and non-alexithymia (NA) groups. The GHA demonstrated significantly higher scores on suppressive factor in Emotional Expressivity Scale (EES) and Emotion Regulation Questionnaire (ERQ). The introvert-high alexithymia (IHA) group also demonstrated higher scores in suppressive tendency in expressing emotion but adopting more reappraisal strategies in regulating emotion than the GHA group. The non-alexithymia (NA) exhibited the highest will to express their emotions and to choose more reappraisal strategies to regulate their emotions, and was associated with the least depressive and anxiety problems. The extrovert-high alexithymia (EHA) were modest between NA and GHA groups.

\section{Discussion}

The major findings of this study showed there were four subtypes of alexithymia and were consistent with previous studies. For example, Vorst and Bermond [25] suggested that there were two types of alexithymia characterized by the emotional and cognitive factors of the Bermond-Vorst Alexithymia Questionnaire (BVAQ) [26]. They proposed that Type I alexithymia is characterized by a low degree of conscious awareness of emotional arousal and a low degree of emotion accompanying cognitions; whereas Type II alexithymia is characterized by a normal or high degree of conscious awareness of emotional arousal together with a low degree of emotion accompanying cognitions. Our cluster analysis showed that there were 4 subtypes of participants associating with different degrees of alextithymia in the college students, namely the extroverted-high alexithymia (EHA), general-high alexithymia (GHA), introversive-high alexithymia (IHA) and non-alexithymia (NA). The GHA was characterized by a general low 
Table 1 Description of subtypes of alexithymia

\begin{tabular}{|c|c|c|c|c|c|c|}
\hline \multirow[t]{3}{*}{ Subtype } & $\begin{array}{c}\text { Extrovert-high } \\
\text { alexithymia group }\end{array}$ & $\begin{array}{c}\text { General-high } \\
\text { alexithymia group }\end{array}$ & $\begin{array}{c}\text { Introvert-high } \\
\text { alexithymia group }\end{array}$ & $\begin{array}{c}\text { Non-alexithymia } \\
\text { group }\end{array}$ & $F$ & $P$ \\
\hline & $\mathrm{N}=1382(77.3 \%)$ & $\mathrm{N}=43(2.4 \%)$ & $\mathrm{N}=47(2.6 \%)$ & $N=316(17.7 \%)$ & & \\
\hline & Mean \pm SD & Mean \pm SD & Mean \pm SD & Mean \pm SD & & \\
\hline \multicolumn{7}{|l|}{ Alexithymia characteristics } \\
\hline $\begin{array}{l}\text { Score of Difficulty Identifying } \\
\text { Feelings factor of TAS- } 20\end{array}$ & $17.66 \pm 3.20$ & $27.47 \pm 3.81$ & $24.68 \pm 2.55$ & $11.37 \pm 2.76$ & 597.81 & $<0.001^{* *}$ \\
\hline $\begin{array}{l}\text { Score of Difficulty Describing } \\
\text { Feelings factor of TAS- } 20\end{array}$ & $13.56 \pm 2.42$ & $17.49 \pm 2.93$ & $15.13 \pm 3.89$ & $9.95 \pm 2.36$ & 236.07 & $<0.001^{* *}$ \\
\hline $\begin{array}{l}\text { Score of Externally Oriented } \\
\text { cognitive style of Thinking factor } \\
\text { of TAS- } 20\end{array}$ & $20.39 \pm 3.00$ & $24.33 \pm 3.78$ & $15.00 \pm 2.45$ & $15.56 \pm 3.34$ & 278.71 & $<0.001^{* *}$ \\
\hline Total score of TAS-20 & $51.62 \pm 6.12$ & $69.28 \pm 4.92$ & $54.81 \pm 5.47$ & $36.87 \pm 4.47$ & 718.74 & $<0.001^{* *}$ \\
\hline \multicolumn{7}{|l|}{ Demographic data } \\
\hline Age (years) & $20.49 \pm 1.28$ & $21.10 \pm 1.08$ & $20.40 \pm 1.36$ & $20.39 \pm 1.19$ & 3.20 & 0.02 \\
\hline Education (years) & $14.81 \pm 1.09$ & $15.23 \pm 1.37$ & $14.94 \pm 1.09$ & $14.70 \pm 1.02$ & 3.85 & 0.01 \\
\hline
\end{tabular}

Note: TAS-20 $=20$-itemToronto alexithymia scale, ${ }^{*} \mathrm{P}<0.05,{ }^{*} \mathrm{P}<0.01$ (two-detailed).

profile of emotional cognition including identifying, describing self emotion and external imagination. The general-high alexithymia (GHA) was similar to Type I alexithymia mentioned by Vorst. The introversive-high alexithymia (IHA) was dominant by low arousal of self emotional experience but normal ability of externally oriented thinking style, which was very similar to Type II. The extroverted-high alexithymia (EHA) is characterized by a normal range of self emotional arousal and a profile score of externally oriented thinking style. These features were very similar to those of Type II alexithymia.
Validation of the cluster solution suggested that these subtypes of alexithymia were characterized by different emotional expression and regulation abilities. The general-high alexithymia (GHA) and introversivehigh alexithymia (IHA) were characterized by poorer emotional regulation and expression with worse emotion status. In more details description, the extroverted-high alexithymia (EHA) seemed to be modest in emotion status, with emotion regulating more efficiently as compared to the general-high alexithymia (GHA). These results suggest the potential functional outcome of these different subtypes. Mattila [27] found

Table 2 Emotional status, emotional expression and regulation traits among subtypes of alexithymia (ANOVA)

\begin{tabular}{|c|c|c|c|c|c|c|c|}
\hline & $\begin{array}{l}\text { Extrovert-High } \\
\text { Alexithymia } \\
\text { group } \\
(\mathrm{N}=1382)\end{array}$ & $\begin{array}{c}\text { General-High } \\
\text { Alexithymia group } \\
(\mathrm{N}=43)\end{array}$ & $\begin{array}{c}\text { Introvert-High } \\
\text { Alexithymia group } \\
(\mathrm{N}=47)\end{array}$ & $\begin{array}{c}\text { Non- } \\
\text { Alexithymia } \\
\text { group } \\
(\mathrm{N}=316)\end{array}$ & $\mathrm{F}$ & $p$ & $\begin{array}{l}\text { Between groups } \\
\text { comparisons }\end{array}$ \\
\hline & Mean \pm SD & Mean \pm SD & Mean \pm SD & Mean \pm SD & & & \\
\hline \multicolumn{8}{|l|}{ Emotional Expressivity Scale } \\
\hline $\begin{array}{l}\text { Total score of Emotional } \\
\text { Expressivity Scale }\end{array}$ & $60.26 \pm 9.83$ & $54.33 \pm 12.29$ & $58.45 \pm 14.45$ & $62.60 \pm 11.48$ & 10.33 & $<0.001^{* *}$ & $4>1>2^{*}$ \\
\hline $\begin{array}{l}\text { Suppression factor of Emotional } \\
\text { Expressivity Scale }\end{array}$ & $43.71 \pm 7.37$ & $38.16 \pm 10.49$ & $41.17 \pm 9.95$ & $45.81 \pm 8.42$ & 16.58 & $<0.001^{* *}$ & $4>1>2^{*}, 4>3^{*}$ \\
\hline $\begin{array}{l}\text { Expression factor of Emotional } \\
\text { Expressivity Scale }\end{array}$ & $16.54 \pm 4.42$ & $16.16 \pm 5.72$ & $17.28 \pm 5.91$ & $16.79 \pm 4.94$ & 0.72 & 0.541 & $\begin{array}{l}\text { No group } \\
\text { difference }\end{array}$ \\
\hline \multicolumn{8}{|l|}{$\begin{array}{l}\text { Emotion regulation } \\
\text { questionnaire }\end{array}$} \\
\hline $\begin{array}{l}\text { Reappraisal factor of Emotion } \\
\text { regulation questionnaire }\end{array}$ & $29.30 \pm 5.35$ & $26.09 \pm 7.61$ & $30.49 \pm 5.94$ & $31.98 \pm 6.40$ & 25.82 & $<0.001^{* *}$ & $4>1,2^{* *}, 3>2^{*}$ \\
\hline $\begin{array}{l}\text { Suppression factor of Emotion } \\
\text { regulation questionnaire }\end{array}$ & $14.67 \pm 3.96$ & $16.74 \pm 5.10$ & $14.57 \pm 5.10$ & $12.82 \pm 4.69$ & 21.75 & $<0.001^{* *}$ & $1,2>4^{*}$ \\
\hline \multicolumn{8}{|l|}{ Emotional status } \\
\hline $\begin{array}{l}\text { score of Beck Depression } \\
\text { Inventory }\end{array}$ & $7.37 \pm 7.61$ & $14.79 \pm 10.53$ & $12.06 \pm 9.98$ & $3.27 \pm 4.70$ & 51.87 & $<0.001^{* *}$ & $2,3>1>4^{*}$ \\
\hline $\begin{array}{l}\text { Trait score of Stat and Trait } \\
\text { anxious inventory. }\end{array}$ & $43.42 \pm 7.11$ & $51.16 \pm 12.34$ & $48.62 \pm 10.31$ & $36.77 \pm 7.62$ & 99.11 & $<0.001^{* *}$ & $2,3>1>4^{*}$ \\
\hline
\end{tabular}

Note: ${ }^{*} \mathrm{P}<0.05$, ${ }^{*} \mathrm{P}<0.01$ (two-detailed). 
that individuals with alexithymia showed significantly lower satisfaction to many dimensions of general life than individuals without alexithymia. Our current findings also showed that individuals with general-high alexithymia (GHA) and introversive-high alexithymia (IHA) tended to show less effective ways to regulate their emotion and might face more stress in their social life than other groups. These findings highlight the need for timely and appropriate psychological counseling for these individuals. The characteristics associated with the different clusters of individuals with alexithymia suggest that regulation ability of alexithymia may require different intervention regimes to protect or maintain their own emotional regulation and expression.

It should be noted that the EHA cluster includes the $77.3 \%$ of the sample. The EHA cluster shows alterations mostly on externally oriented cognitive style of thinking (EOT). Some studies showed difficulty identifying feelings (DIF) and difficulty describing feelings (DDF) had good internal reliability but not EOT [28]. Some researcher thought EOT dimension showed different development paths companying with DDI and DDF [29]. Moreover, it should also be cautious that the clusters we found in the current study may not be stable at all in time and/or it is an artefact due to the instruments that have been used by the current study. It should be necessary to reassess the students to evaluate validity. Without a longitudinal approach any speculation in the discussion should be shown just as an hypothesis to be confirmed. Our results indicated that most of the cases were clustered into extroverted-high alexithymia (EHA) and suggested alexithymia might be a general phenomenon of an emotion processing ability distributed in the general population. More investigations were needed to clarify the relation of alexithymia and personality.

The current study has several limitations. First, participants were recruited from a convenient sample pool was the main limitation of this study. Whether these cluster groups could discovered in more broad population needs future study adopted a more rigorous epidemiological approach to improve its representativeness. Second, the findings were based on subjective self-report measures. More rigorous methodologies adopting experimental designs or neurophysiological approaches such as ERP or imaging paradigms should be enforced in the near future in order to validate potential differential neural bases of these subtypes of alexithymia. Finally, the current cross-sectional design could not examine the stability of the cluster solutions across different time points. Future study should adopt a longitudinal design to test the stability of the cluster solution.

\section{Conclusions}

The current findings suggest there were four subtypes of alexithymia characterized by different emotional regulation manifestations.

\section{Abbreviations}

ANOVA: analysis of variance; BDI: Beck Depression Inventory; BVAQ: Bermond-Vorst Alexithymia Questionnaire; DDF: difficulty describing feelings; DIF: difficulty identifying feelings; EES: Emotional Expressivity Scale; EHA: extrovert-high alexithymia; EOT: externally oriented cognitive style of thinking; ERP: Event-related Potential; ERQ: Emotion Regulation

Questionnaire; FFM: Five-Factor Model; GHA: general-high alexithymia, IHA: introvert-high alexithymia; NA: non-alexithymia; SPSS: Statistical Package for Social Sciences; STAI-T: Trait portion of the State-Trait Anxiety inventory; TAS20: 20-item Toronto alexithymia scale.

\section{Acknowledgements}

This study was supported partially by the Project-Oriented Hundred Talents Programme (O7CX031003), the Knowledge Innovation Project of the Chinese Academy of Sciences (KSCX2-YW-R-131), and a grant from the National Basic Research Programme of China (973 Program) (2007CB512302) to Raymond Chan.

\section{Author details}

'Department of Maternal and Child Health, school of Public Health, Sun YatSen University, Guangzhou, PR China. ${ }^{2}$ Neuropsychology and Applied Cognitive Neuroscience Laboratory; Key Laboratory of Mental Health, Institute of Psychology, Chinese Academy of Sciences, Beijing, PR China. ${ }^{3}$ Mental Health Education \& Counseling Center, Sun Yat-sen University, Guangzhou, PR China. ${ }^{4}$ Graduate School, Chinese Academy of Sciences, Beijing, PR China.

\section{Authors' contributions}

JC designed the study, collected and analyzed data, and wrote the first draft of the manuscript. RCKC conceived and designed the study, and wrote the first draft of the paper. TX analyzed data and participated in writing up the manuscript. JJ participated in writing up the manuscript. All authors read and approved the final manuscript

\section{Competing interests}

The authors declare that they have no competing interests.

Received: 8 November 2010 Accepted: 23 February 2011 Published: 23 February 2011

\section{References}

1. Sifneos PE: The prevalence of "alexithymic" characteristics in psychosomatic patients. Psychotherapy and Psychosomatics 1973, 22(26):255-262.

2. Taylor G, Bagby RM, Luminet O: Assessment of Alexithymia: Self-report and Observer-rated Measures. In The handbook of emotional intelligence. In J.D.A. Parker and R. Bar-On edition. Edited by: Parker JDAaB-O R. San Francisco: CA: Jossey Bass; 2000:301-319.

3. Honkalampi K, Hintikka J, Laukkanen E, Lehtonen J, Viinamaki H: Alexithymia and Depression:A Prospective Study of Patients With Major Depressive Disorder. Psychosomatics 2001, 42:229-234.

4. Berthoz S, Consoli SM, Perez-Diaz F, Jouvent R: Alexithymia and anxiety: compounded relationships? A psychometric study. European Psychiatry 1999, 14(7):372-378.

5. Cedro A, Kokoszka A, Popiel A, Narkiewicz-Jodko W: Alexithymia in schizophrenia: an exploratory study. Psychol Rep 2001, 89(1):95-98

6. Ridout N, Thom C, Wallis DJ: Emotion recognition and alexithymia in females with non-clinical disordered eating. Eating Behaviors 2010, 11(1):1-5.

7. Huber A, Suman AL, Biasi G, Carli G: Alexithymia in fibromyalgia syndrome: Associations with ongoing pain. Journal of Psychosomatic Research 2009, 66(5):425-433. 
8. Mehling WE, Krause N: Are difficulties perceiving and expressing emotions associated with low-back pain? The relationship between lack of emotional awareness (alexithymia) and 12-month prevalence of lowback pain in 1180 urban public transit operators. Journal of Psychosomatic Research 2005, 58(1):73-81.

9. Hexel M: Alexithymia and attachment style in relation to locus of control. Personality and Individual Differences 2003, 35(6):1261-1270.

10. Zimmermann G, Rossier J, Meyer de Stadelhofen F, Gaillard F: Alexithymia Assessment and Relations with Dimensions of Personality. European Journal of Psychological Assessment 2005, 21(1):23-33.

11. Mattila AK, Keefer KV, Taylor GJ, Joukamaa M, Jula A, Parker JDA, Bagby RM: Taxometric analysis of alexithymia in a general population sample from Finland. Personality and Individual Differences 2010, 49(3):216-221.

12. Parker JDA, Keefer KV, Taylor GJ, Bagby RM: Latent Structure of the Alexithymia Construct: A Taxometric Investigation. Psychological Assessment 2008, 20(4):385-396.

13. Parker JDA, Taylor GJ, Bagby RM: The 20-Item Toronto Alexithymia Scale: III. Reliability and factorial validity in a community population. Journal of Psychosomatic Research 2003, 55(3):269-275.

14. Taylor GJ, Bagby RM, Parker JDA: The 20-Item Toronto Alexithymia Scale IV. Reliability and factorial validity in different languages and cultures. Journal of Psychosomatic Research 2003, 55(3):277-283.

15. Zhu X, Yi J, Yao S, Ryder AG, Taylor GJ, Bagby RM: Cross-cultural validation of a Chinese translation of the 20-item Toronto Alexithymia Scale. Comprehensive Psychiatry 2007, 48(5):489-496.

16. Yi J, Yao S, Zhu X: The Chinese version of the TAS-20: reliability and validity. Chinese Mental Health Journal 2003, 17(11):763-766.

17. Kring AM, Smith DA, Neale JM: Individual differences in dispositional expressiveness: Development and validation of the Emotional Expressivity Scale. Journal of Personality and Social Psychology 1994, 66(5):934-949.

18. Chan RCK, Wang Y, Li H, Shi Y, Wang Y, Liu W, Huang J: A 2-stage factor analysis of the Emotional Expressivity Scale in the Chinese context. Psychologia 2010, 53:144-150.

19. John OP, Gross Jj: Healthy and Unhealthy Emotion Regulation:Personality Processes, Individual Differences, and Life Span Development. Journal of Personality 2004, 72(6):1301-1334.

20. Wang L, Liu H, Li Z: Reliability and Validity of Emotion Regulation Questionnaire Chinese Revised Version. China Journal of Health Psychology 2007, 15(6):503-505.

21. Beck AT, Steer RA, Carbin MG: Psychometric properties of the Beck Depression Inventory: Twenty-five years of evaluation. Clinical Psychology Review 1988, 8(1):77-100.

22. Kendall PC, Hollon SD, Beck AT, Hammen CL, Ingram RE: Issues and recommendations regarding use of the Beck Depression Inventory. Cognitive Therapy and Research 1987, 11(3):289-299.

23. Zheng YP, Lin KM: Comparison of the Chinese Depression Inventory and the Chinese version of the Beck Depression Inventory. Acta Psychiatr Scand 1991, 84(6):531-536.

24. Shek DTL: Reliability and Factorial Structure of the Chinese Version of the State-Trait Anxiety Inventory. Journal of Psychopathology and Behavioral Assessment 1988, 10(4):303-317.

25. Bermond B, Clayton K, Liberova A, Luminet O, Maruszewski T, Bitti PER, Rimé $\mathrm{B}$, Vorst $\mathrm{HH}$, Wagner $\mathrm{H}$, Wicherts $\mathrm{J}$ : A cognitive and an affective dimension of alexithymia in six languages and seven populations. Cognition and Emotion 2007, 21(5):1125-1136.

26. Vorst HCM, Bermond B: Validity and reliability of the Bermond-Vorst Alexithymia Questionnaire. Personality and Individual Differences 2001, 30(3):413-434.

27. Mattila AK, Saarni SI, Alanen E, Salminen JK, Kronholm E, Jula A, Sintonen H, Joukamaa M: Health-related quality-of-life profiles in nonalexithymic and alexithymic subjects from general population. Journal of Psychosomatic Research 2010, 68(3):279-283.

28. Taylor GJ, Bagby RM, Parker JDA: The 20-Item Toronto Alexithymia Scale IV. Reliability and factorial validity in different languages and cultures. Journal of Psychosomatic Research 2003, 55(3):277-283.

29. Moriguchi Y, Maeda M, Igarashi T, Ishikawa T, Shoji M, Kubo C, Komaki G: Age and gender effect on alexithymia in large, Japanese community and clinical samples: a cross-validation study of the Toronto Alexithymia Scale (TAS-20). BioPsychoSocial Medicine 2007, 1(7):1-15.

\section{Pre-publication history}

The pre-publication history for this paper can be accessed here: http://www.biomedcentral.com/1471-244X/11/33/prepub

doi:10.1186/1471-244X-11-33

Cite this article as: Chen et al:: Alexithymia and emotional regulation: $\mathrm{A}$ cluster analytical approach. BMC Psychiatry 2011 11:33.

\section{Submit your next manuscript to BioMed Central and take full advantage of:}

- Convenient online submission

- Thorough peer review

- No space constraints or color figure charges

- Immediate publication on acceptance

- Inclusion in PubMed, CAS, Scopus and Google Scholar

- Research which is freely available for redistribution

Submit your manuscript at www.biomedcentral.com/submit
C) Biomed Central 